\title{
Deflated Balloon-Facilitated Direct Stenting in Primary Angioplasty (The DBDS Technique): A Pilot Study
}

\author{
Bhupendra Verma $^{\mathrm{a}, \mathrm{b}}$, Amrita Singh ${ }^{\mathrm{a}}$, Ashwani K Saxena ${ }^{\mathrm{a}}$, Manu Kumar ${ }^{\mathrm{a}}$
}

\begin{abstract}
Background: Several studies and meta-analyses have shown that direct stenting (DS) may improve clinical outcomes in patients with acute ST-elevation myocardial infarction (STEMI). But in most cases, the thrombolysis in myocardial infarction (TIMI) flow remains $\leq 1$ after wire placement. We used deflated balloon to facilitate DS in patients with totally occluded culprit arteries. The aim of this study was to evaluate the feasibility, safety and outcomes of this novel technique in patients with STEMI in real-world clinical practice.
\end{abstract}

Methods: This was a prospective, observational, single-center pilot study. From September 2016 to June 2018, 454 patients were enrolled in the study. DS was performed when the culprit vessel was visualized with at least TIMI flow grade 1. Patients with complete occlusion of the vessel after wire placement were subjected to deflated balloonfacilitated DS technique (DBDS technique) and DS was done wherever possible.

Results: DS was done in $74 \%(\mathrm{n}=336)$ of the patients and $26 \%$ $(\mathrm{n}=118)$ patients received stenting after pre-dilatation (PD). DBDS technique to facilitate DS was successful in $68 \%$ patients $(211 / 309)$. Final TIMI 3 flow was achieved more frequently in the DS group as compared to PD group $(96.7 \%$ versus $92.3 \%, \mathrm{P}=0.04)$. The procedural complications were also significantly lower in DS group $(0.6 \%$ versus $7.6 \%, \mathrm{P}<0.001)$. DS group had significantly lower procedure time ( $33 \pm 19 \mathrm{~min}$ versus $41 \pm 17 \mathrm{~min}, \mathrm{P}<0.001)$, fluoroscopy time $(6.2 \pm 3.4 \mathrm{~min}$ versus $7.8 \pm 32 \mathrm{~min}, \mathrm{P}<0.001)$, required lesser contrast volume $(112 \pm 16 \mathrm{~mL}$ versus $123 \pm 18 \mathrm{~mL}, \mathrm{P}<0.001)$ and had lower procedural cost $(310 \pm 45 \$$ versus $402 \pm 56 \$, \mathrm{P}<0.001)$. STsegment resolution $>50 \%$ after percutaneous coronary intervention (PCI) were significantly higher in the DS group $(85.7 \%$ versus $71.1 \%$, $\mathrm{P}<0.001$ ). At 30 days, the major adverse cardiac event (MACE) rate was significantly lower in the DS group $(2.4 \%$ versus $9.3 \%, \mathrm{P}=0.02)$, mainly driven by lower rates of target lesion revascularization (TLR) $(0.9 \%$ versus $4.2 \%, \mathrm{P}=0.01)$.

Conclusion: This cost-effective technique appears to be simple,

Manuscript submitted July 30, 2018, accepted September 27, 2018

${ }^{a}$ Department of Cardiology, Shree Krishna Hospital, Kashipur, UK, India ${ }^{b}$ Corresponding Author: Bhupendra Verma, Shree Krishna Hospital and Heart Centre, Kashipur-244713, US Nagar, UK, India.

Email: bhupendra.269@gmail.com

doi: https://doi.org/10.14740/cr770w feasible and safe and is associated with superior clinical outcomes. It helps in maximizing DS and could offer an alternative to PD and aspiration thrombectomy in total occlusion. However, larger studies with longer follow up are required before a wider application of this technique.

Keywords: ST elevation myocardial infarction; Percutaneous coronary intervention; Technique; Pre-dilatation; Thrombus aspiration; Outcomes; Acute coronary syndrome; Cost benefit

\section{Introduction}

ST-elevation myocardial infarction (STEMI) is characterized by thrombotic occlusion of the coronary artery precipitated by plaque rupture. Primary percutaneous coronary intervention (PPCI) remains the treatment of choice because it is associated with a significant reduction in morbidity and mortality [1, 2]. Most procedures are now performed with drug-eluting stents, which are associated with a lower rate of restenosis than bare-metal stents. Distal embolization during PCI is a major contributor to microvascular injury, resulting in persistent STsegment changes, larger infarct size, hemodynamic instability and death [3]. Pharmacologically facilitated PCI has resulted in increased bleeding risk and failed to provide improvements in clinical outcomes [4]. Balloon inflation is associated with higher risk of distal embolization and microvascular occlusion, which is associated with worse outcomes [5]. Moreover, recent randomized clinical trials and meta-analyses showed that the routine use of aspiration thrombectomy in STEMI was not associated with any benefit on short-term outcomes $[6,7]$.

Considering this, direct stenting appears to be the current best option for PPCI. The availability of low-profile stent delivery systems has further provided impetus to DS. Studies have shown that DS shortens procedural time, reduces radiation and contrast exposure and has lower adverse event rate [8]. To perform DS, it is mandatory to visualize the length of culprit lesion and the diameter of the downstream artery. Unfortunately, in most cases of STEMI, the thrombolysis in myocardial infarction (TIMI) flow remains $\leq 1$ after wire placement. Therefore, the feasibility of DS has been quite low ranging from $30 \%$ to $50 \%$. We utilized a deflated balloon to facilitate DS by visualization of culprit lesion, in patients with total occlusion of the culprit artery. The aim of this study was to evaluate the feasibility, safety and outcomes of this novel technique in pa- 


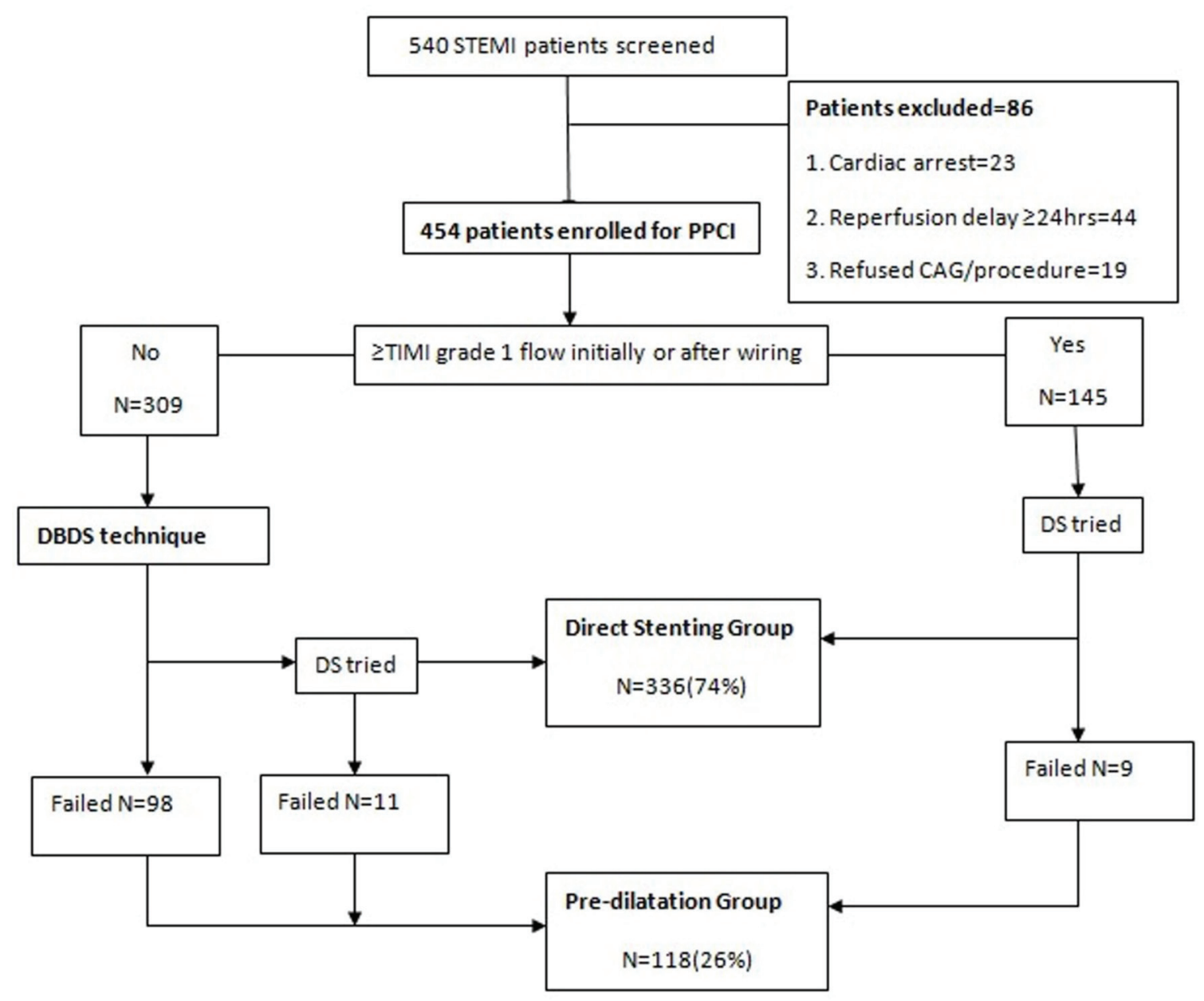

Figure 1. The study flow summarizing the study design.

tients with STEMI in real-world clinical practice.

\section{Material and Methods}

\section{Study population}

This was a prospective, observational, single-center study. From September 2016 to June 2018, 540 consecutive patients with STEMI who were referred for primary PCI were screened for inclusion in the study. All patients $>18$ years of age presenting with STEMI within $12 \mathrm{~h}$ of symptom onset or between 12 and $24 \mathrm{~h}$ if they had persistent symptoms with evidence of ongoing ischemia, were included in the study for PPCI. Patients who presented with cardiac arrest, with reperfusion delay $>24 \mathrm{~h}$ and/or not giving consent for the procedure were excluded. DS was the primary modality of treatment in all patients wherever possible. All patients where DS was done formed the direct stenting group (DS group, and rest were included in the pre-dilatation group (PD group). Patients in the PD group underwent balloon pre-dilatation \pm thrombosuction prior to stenting. The flow chart in Figure
1 summarizes the study design. The study was approved by the local ethical committee and all patients provided written informed consent.

\section{Study protocol}

During primary PCI, those patients who had TIMI flow of $\geq$ 1 at initial injection or after wire placement underwent DS. Patients with complete occlusion of the vessel after wire placement were subjected to deflated balloon-facilitated DS technique (DBDS technique). In this technique, a semi-compliant balloon was taken with diameter $\leq 2 \mathrm{~mm}$ and length $\leq 15 \mathrm{~mm}$. It was gently crossed beyond the lesion in deflated state and pulled back into the guiding catheter. Thereafter, a small (2 - 3 $\mathrm{mL}$ of contrast agent) injection was taken to assess the distal TIMI grade flow. If TIMI flow $\geq 1$ was achieved and distal end of lesion was visualized, DS was done (Fig. 2). If flow could not be achieved, the balloon crossing was repeated with contrast injections to a maximum of three times. In many cases, the distal flow would last for few seconds; therefore, an immediate visual estimation of lesion or fluoroscopy grab image was used for DS. If flow still remained $\leq$ TIMI 1, the same balloon 

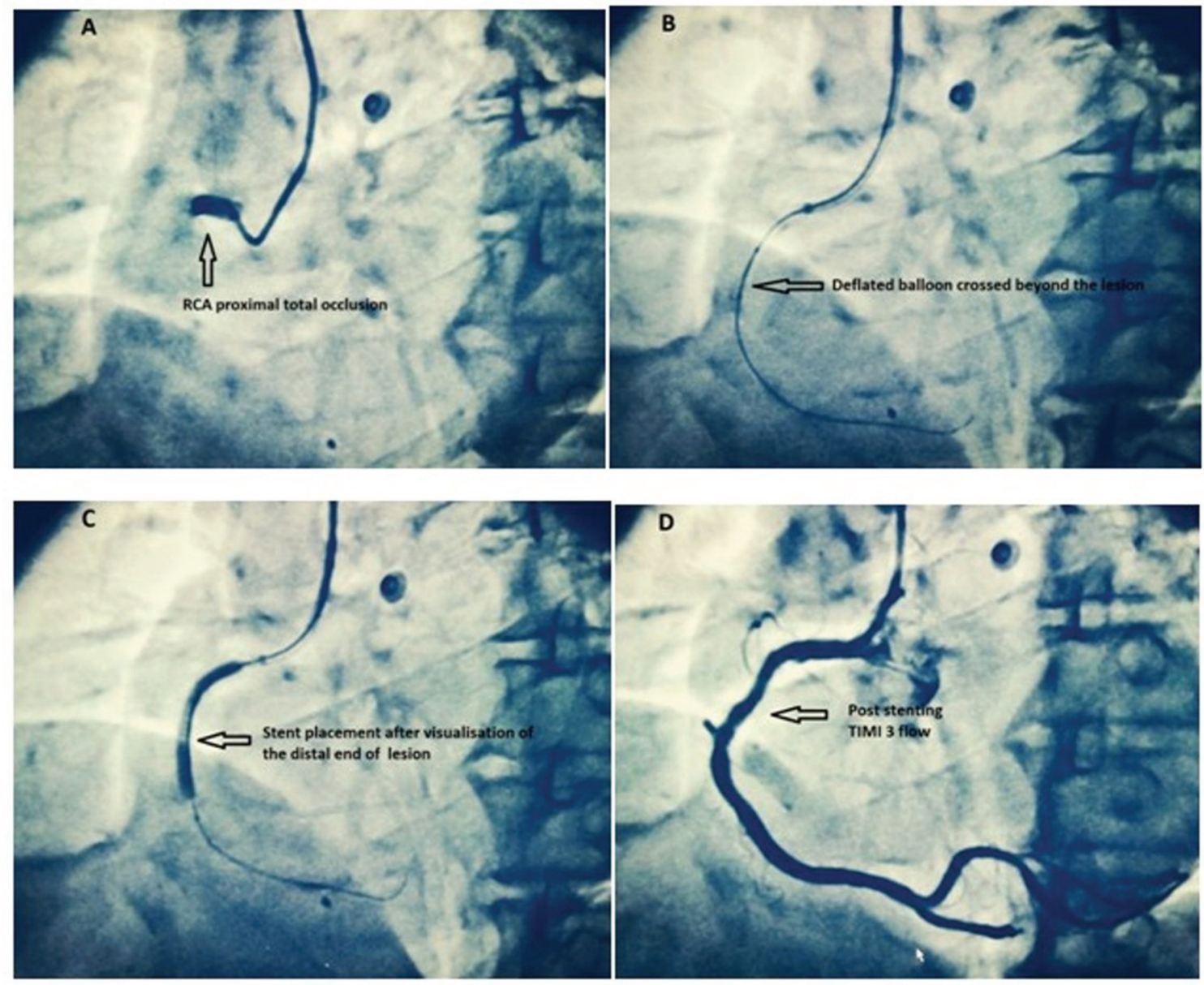

Figure 2. RCA total occlusion treated with the DBDS technique. (a) Complete thrombotic occlusion of proximal RCA with no distal flow (TIMI 0). (b) After wiring, a deflated balloon is gently crossed beyond the lesion and pulled back. (c) Direct stent placement is done after visualization of the distal end of lesion ( $\geq$ TIMI grade 1 flow achieved by DBDS technique). (d) Final result with a TIMI flow of 3 after stenting. RCA: right coronary artery; TIMI: thrombolysis in myocardial infarction.

was advanced across the lesion and used for pre-dilatation.

All the patients underwent loading with ticagrelor 180 $\mathrm{mg}$, aspirin $300 \mathrm{mg}$ and atorvastatin $80 \mathrm{mg}$ in the emergency department itself. During the procedure, intravenous UFH (Un-fractionated Heparin) was for anticoagulation and glycoprotein IIb/IIIa inhibitors were used as bail-out only. Secondgeneration drug-eluting stents (DES) were used in all cases and the stent length was kept greater than the lesion length to prevent plaque and thrombus shift. If the patient was in cardiogenic shock, PCI of non-IRA lesions (infarct related artery) was done during index procedure, otherwise it was routinely done before hospital discharge. Aspiration thrombectomy was very selectively used in cases with heavy thrombotic burden and where downstream artery couldn't be visualised. Whenever we found TIMI flow $\geq 1$ either at baseline or after wiring, an immediate fluoroscopy grab was done to proceed for DS, as in many cases the artery would reocclude and thereby unnecessarily require pre-dilatation \pm thrombosuction. Postdilation and high-pressure ( $\geq 14 \mathrm{~atm}$ ) stent deployment was avoided because of high thrombotic burden in acute STEMI and risk of distal embolization. Wherever feasible, we pre- ferred using slightly oversized stent and deployment at low pressures (10-12 atm). Intracoronary nicorandil and/or adenosine injections were selectively used in patients with slow flow or no-reflow after stenting. Every attempt was made to minimise fluoroscopy time and contrast volume. Visipaque (GE Healthcare, Chicago, IL) was used as contrast agent and hydration with isotonic saline was done in all patients pre and post procedure. After the intervention, all patients received aspirin indefinitely, clopidogrel, prasugrel or ticagrelor (preferably) for at least 12 months and other cardiac medications according to ACC/AHA guidelines [9]. Patients remained in hospital for at least $48 \mathrm{~h}$.

\section{Study endpoints}

The procedural outcomes recorded were TIMI flow at the end of the procedure, use of Gp IIb/IIIa inhibitors, contrast volume use, fluoroscopy time, procedural time, overall procedural cost and procedural complications. The clinical outcomes recorded were the rates for ST-segment resolution $>50 \%$ after PCI, left 
Table 1. Patient Characteristics

\begin{tabular}{llll}
\hline & DS group $(\mathbf{n}=\mathbf{3 3 6})$ & PD group $(\mathbf{n}=\mathbf{1 1 8})$ & P value \\
\hline Age $($ years $)$, mean \pm SD & $53.9 \pm 10$ & $52.8 \pm 11$ & 0.31 \\
Male sex & $264(78.5)$ & $95(80.5)$ & 0.65 \\
BMI, mean \pm SD & $26.5 \pm 6.2$ & $25.9 \pm 6.7$ & 0.37 \\
Diabetes & $97(28.8)$ & $44(37.2)$ & 0.08 \\
Hypertension & $207(61.6)$ & $68(57.6)$ & 0.44 \\
Dyslipidemia & $131(38.9)$ & $42(35.5)$ & 0.51 \\
Current smoker & $151(45)$ & $71(60.1)$ & 0.004 \\
Family history of CAD & $41(12.2)$ & $16(13.5)$ & 0.70 \\
Prior MI & $24(7.1)$ & $10(8.4)$ & 0.63 \\
Prior PCI & $9(2.6)$ & $4(3.3)$ & 0.58 \\
LVEF, mean \pm SD & $39.9 \pm 6.4$ & $38.2 \pm 7.3$ & 0.01 \\
\hline
\end{tabular}

Values shown represent numbers (percentages), except where otherwise noted. DS: direct stenting; PD: pre-dilatation; BMI: body mass index; CAD: coronary artery disease; MI: myocardial infarction; PCl: percutaneous coronary intervention; LVEF: left ventricular ejection fraction.

ventricular ejection fraction (LVEF) at discharge, cardiogenic shock, ventricular fibrillation, all-cause death, stent thrombosis and a composite of major adverse cardiac events (i.e. cardiac death, non-fatal myocardial infarction and clinical driven target lesion revascularization (TLR)) at 30-day follow-up. The primary endpoint was the feasibility of the procedure and the secondary endpoint was a composite of major adverse cardiac events (MACE) at 30 days.

\section{Definitions}

DS was defined as stent implantation without the use of aspiration thrombectomy or a balloon pre-dilation. Success of the DBDS technique was defined as $\geq 1$ TIMI grade 1 flow after the procedure. Any death was defined as cardiac unless an unequivocal non-cardiac cause could be established. Stent thrombosis was determined angiographically or, in the absence of angiographic confirmation, as sudden cardiac death within 30 days of implantation or myocardial infarction in the territory of the target vessel, as per Academic Research Consortium (ARC) definite or probable criteria [10]. TLR was defined as any clinically indicated repeat revascularization of the target vessel performed for restenosis or other complication of the target lesion [10]. Major adverse cardiac event (MACE) was defined as the composite rate of cardiac death, MI and TLR. TIMI flow grading and myocardial blush grade (MBG) were used together to define angiographic no reflow as TIMI flow < 3 (with any MBG grade) or TIMI flow 3 with MBG 0 - 1 [11].

\section{Statistical analysis}

The data were analyzed using GraphPad Prism 7, version 7.04 (GraphPad Software, Inc.). Baseline, procedural and follow-up information were summarized with descriptive statistics. Continuous variables were presented as means and SDs and categorical variables were expressed as frequencies and percent- ages. The $\mathrm{P}$ value for comparing two independent continuous variables was from unpaired student's $t$-test and for comparing two proportions was from the chi-square test or Fisher exact test. All tests were two-sided, and statistical significance was at $\mathrm{P}<0.05$.

\section{Results}

\section{Patient characteristics}

From September 2016 to June 2018, 540 consecutive patients with STEMI admitted to our hospital were screened and 454 patients were enrolled in the study after exclusion. Out of these, 336 patients (74\%) were included in DS group and 118 patients $(26 \%)$ formed the PD group. The flow chart in Figure 1 shows the summary of study design. As shown in Table 1, the two groups were comparable with regard to most of the demographic and baseline clinical characteristics. However, there were significantly higher number of smokers in PD group and the baseline LVEF too was lower.

\section{Primary outcome: feasibility of the technique}

After angiography, 93 patients $(20.4 \%, n=454)$ had $\geq 1$ TIMI grade 1 flow in the infarct-related artery. Subsequently after wiring, additional 52 patients $(11.4 \%, \mathrm{n}=454)$ developed flow suitable for DS. The remaining 309 patients with total occlusion even after wiring, were subjected to DBDS technique. The success rate of the technique was 68\% (211/309). Overall, DS was done in $74 \%$ of the total patients as compared to $32 \%$, where it would have been possible without the technique $(\mathrm{P}$ $<0.0001)$. Possible complication of the technique was noted only in one patient who developed no-reflow, which improved with intracoronary nicorandil. The failure rate of DS in patients with $\geq 1$ TIMI grade 1 flow, either at baseline or after 
Table 2. Procedural Characteristics and Outcomes

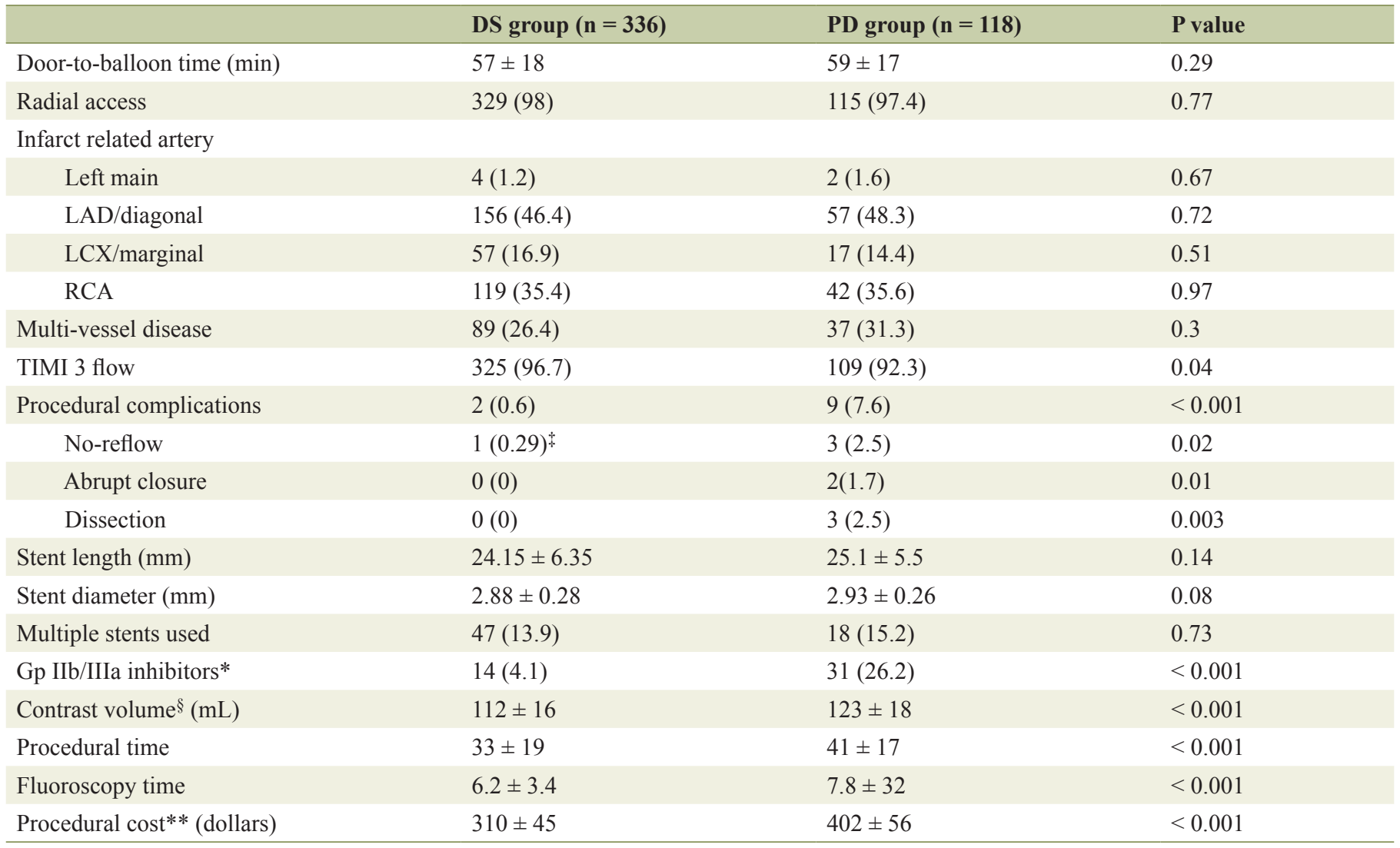

Values shown represent numbers (percentages), except where otherwise noted. DS: direct stenting; PD: pre-dilatation; LAD: left anterior descending

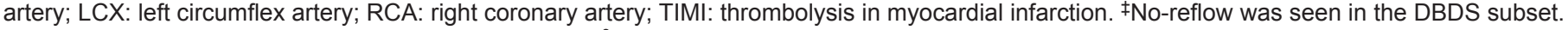
*Bail-out Gp Ilb/Illa inhibitor use. **Excluding stent cost. §Contrast media Visipaque (GE Healthcare, Chicago, IL, USA) was used in all cases.

DBDS, was 5.6\%(20/356).

\section{Procedural characteristics and outcomes}

Table 2 shows the procedural characteristics in both groups. The door to balloon time was $57 \pm 18 \mathrm{~min}$ in DS group versus $59 \pm 17 \mathrm{~min}$ in PD group $(\mathrm{P}=0.29)$. Transradial approach was the primary modality in both groups $(98 \%$ versus $97.4 \%, \mathrm{P}=$ 0.77). In both groups, the culprit arteries were most frequently the left anterior descending artery and right coronary artery. Prevalence of multivessel disease was also similar.

Final TIMI 3 flow was achieved more frequently in the DS group (96.7\% versus $92.3 \%, \mathrm{P}=0.04)$. The procedural complications were also significantly lower in DS group ( $\mathrm{P}$ $<0.001$ ), driven by lower no-reflow, abrupt closure and dissection. The mean stent length, diameter and use of multiple stents were similar in both groups. DS when compared with the PD technique, significantly decreased both procedure time ( $33 \pm 19$ minutes versus $41 \pm 17$ minutes, $\mathrm{P}<0.001)$ and fluoroscopy time $(6.2 \pm 3.4$ min versus $7.8 \pm 32$ minutes, $\mathrm{P}<0.001)$. Moreover, contrast volume used in DS group was significantly lower $(112 \pm 16 \mathrm{~mL}$ versus $123 \pm 18, \mathrm{P}<0.001)$. Overall procedural cost excluding the stent was $310 \pm 45 \$$ in DS group compared to $402 \pm 56 \$$ in $\mathrm{PD}$ group $(\mathrm{P}<0.001)$. Bail-out use of Gp IIb/IIIa inhibitors in DS group too was significantly lower $(4.1 \%$ versus $26.2 \%, \mathrm{P}<0.001)$.

\section{Clinical outcomes}

Table 3 shows the clinical outcomes for both groups. STsegment resolution $>50 \%$ after PCI were significantly higher in the DS group, whereas the LVEF was similar in the two groups. The rates of cardiogenic shock, ventricular fibrillation and stroke during hospitalization were also similar in the two groups.

At 30 days, the MACE rate was significantly lower in the DS group $(2.4 \%$ versus $9.3 \%, \mathrm{P}=0.02)$, mainly driven by lower rates of TLR $(0.9 \%$ versus $4.2 \%, \mathrm{P}=0.01)$. There was no significant difference in mortality rates between the two groups during hospitalization and after 30 days.

\section{Discussion}

PPCI with stenting is the standard of care in STEMI because it is associated with a significant reduction in morbidity and 
Table 3. Clinical Outcomes

\begin{tabular}{llll}
\hline & DS group $(\mathbf{n}=\mathbf{3 3 6})$ & PD group $(\mathbf{n}=\mathbf{1 1 8})$ & P value \\
\hline In-hospital outcomes & & & 0.75 \\
LVEF at discharge & $49.2 \pm 8.8$ & $48.9 \pm 9.2$ & 0.47 \\
Cardiogenic shock & $27(8)$ & $12(10.1)$ & 0.47 \\
Ventricular fibrillation & $3(0.9)$ & $2(1.7)$ & 0.55 \\
Stroke & $1(0.3)$ & $0(0)$ & 0.27 \\
All-cause mortality & $2(0.6)$ & $2(1.7)$ & $<0.001$ \\
ST-segment resolution* & $288(85.7)$ & $84(71.1)$ & \\
30 day outcomes & & & $3(2.5)$ \\
Total death & $3(0.9)$ & $2(1.7)$ & 0.10 \\
Cardiac death & $1(0.3)$ & $4(3.3)$ & 0.11 \\
MI & $4(1.2)$ & $5(4.2)$ & 0.01 \\
TLR & $3(0.9)$ & $1(0.8)$ & 0.43 \\
Stent thrombosis & $1(0.3)$ & $11(9.3)$ & 0.02 \\
MACE** & $8(2.4)$ & & \\
\hline
\end{tabular}

Values shown represent numbers (percentages), except where otherwise noted. DS: direct stenting; PD: pre-dilatation; LVEF: left ventricular ejection fraction; PCl: percutaneous coronary intervention; MI: myocardial infarction; TLR: target lesion revascularization; MACE: major adverse cardiac events. ${ }^{*}$ ST-segment resolution $>50 \%$ after $\mathrm{PCl} .{ }^{* *}$ Composite of cardiac death, myocardial infarction and target lesion revascularization.

mortality as compared to fibrinolysis [2] and balloon angioplasty $[12,13]$. More recently, drug-eluting stents, especially the second generation stents, have been shown to be associated with a significant reduction in the rate of target vessel revascularization [14] and stent thrombosis [15]. To perform stenting, it is mandatory to visualize the length of culprit lesion and the diameter of the downstream artery. However, in a STEMI patient, TIMI flow is most often $\leq 1$ [16]. Balloon PD is associated with more reperfusion failure and lower probability of final TIMI 3 flow [5, 17]. Pharmacologically facilitated PCI has been associated with significant increase in bleeding and has failed to show any improvements in the clinical outcomes [4, 18]. Similarly, recent randomized clinical trials (RCTs) and meta-analyses showed that the routine use of aspiration thrombectomy in STEMI is not associated with any benefit [6] and is recommended only in select patients [7].

As a result DS is currently suggested as the default strategy in primary angioplasty [19]. DS, or stenting without lesion PD, is employed in 30-50\% of PCIs in elective as well as nonelective patients undergoing PCI. Contemporary, second-generation DES is constructed from a thin, highly flexible metal alloy making them more attractive for direct delivery. Prospective studies as well as meta-analyses have consistently demonstrated significant benefit of DS in terms of safety, procedural outcomes, MACE rate and mortality [8]. Superior clinical outcomes associated with DS may be driven by reduced wall damage and inflammatory response from balloon PD [20], greater preservation of residual endothelium [21], better longitudinal centering of the stent on the lesion with more uniform axial redistribution of plaque [22], reduced microcirculatory dysfunction and/or distal embolization [23], significant improvement in myocardial reperfusion [24], higher probability of TIMI 3 flow [25], fewer intimal dissections [26] and consequently lesser requirement of number and length of stents [27]. There are also significant downsides to DS including: underestimation of true vessel size, failure to cross, non-dilatable lesions, inadequate stent expansion, geographic miss, late stent malapposition and restenosis [3].

Due to poor outcomes associated with balloon inflation and thrombectomy, newer techniques are being explored. One study involved microcatheter (MC) facilitated DS, independent of the TIMI flow in the culprit artery. In the MC group, downstream arteries were visualized in $98 \%$ of cases and DS was achieved in $72 \%$ versus $31 \%(\mathrm{P}<0.0001)$ [28]. However, the study was limited by smaller sample size, high cost of MC and increased procedural time. Moreover, the effect of contrast media injection in a non-perfused artery is unknown and might be deleterious to myocardial cells. Another alternative could be deferred stenting in selected STEMI patients undergoing PPCI [29]. However, deferred stenting in studies has shown no impact on MACE, occurrence of no-reflow, death, myocardial infarction or repeat revascularization and even suggested a deleterious effect on microvascular obstruction size [30-32]. Though the available data do not support such strategy, it can be an option in high-risk STEMI patients [33].

We proposed a novel technique to facilitate DS in patients with totally occluded coronary arteries. The use of the DBDS technique can allow the visualization of the downstream artery and assessment of the culprit lesion and hence more frequently allow DS. The success rate of the technique was $68 \%$ in arteries with $\leq 1$ TIMI grade flow after wire placement. Overall, DS was done in $74 \%$ of patients as compared to $32 \%$ after wire placement $(\mathrm{P}<0.0001)$. Complication possibly related to technique was noted only in one patient who developed no-reflow $(0.3 \%)$. This novel strategy appears to be a feasible and safe option for facilitating DS of the culprit vessel. 
DS group had significantly higher final TIMI 3 flow $(96.7 \%$ versus $92.3 \%, \mathrm{P}=0.04)$ and $\mathrm{ST}-$ segment resolution $>$ $50 \%$ after PCI $(85.7 \%$ versus $71.1 \%, \mathrm{P}<0.001)$. The overall procedural complications were also significantly lower in DS group $(0.6 \%$ versus $7.6 \%, \mathrm{P}<0.001)$. These results are similar to the recent EUROTRANSFER registry study where DS resulted in significantly greater rates of postprocedural TIMI grade 3 flow $(91.5 \%$ versus $94.9 \%, \mathrm{P}=0.020)$ and higher rates for ST-segment resolution $>50 \%$ after PCI $(76.3 \%$ versus $86.2 \%, P=0.016$ ) [34]. Likewise, the safety of DS has been established in several meta-analyses $[8,17,35,36]$.

Like the available studies on DS during primary angioplasty, the DS group in our study also had significantly shorter procedural time, lesser radiation and contrast exposure $[8,17$, $35,37,38]$. Cases of cataracts, carotid artery disease and brain tumours reported by interventionalists are supposedly linked to routine exposure to radiation. Anything that can be done to limit exposure to radiation, including reducing procedure steps and time through direct stenting, can have a beneficial impact. Moreover, there was a significant $20 \%$ reduction in procedural cost, as seen in a previous metanalysis [37]. Therefore, this technique appears to be an attractive option particularly for health care in resource poor third world countries like India. We have also reported a lower MACE rate at 30 days of follow up. Furthermore, studies have shown reduction in both shortterm and 1-year mortality in addition to MACE $[17,34,36]$. In this study, the in-hospital mortality and 30 days mortality were numerically lower but not significantly different. However, long term follow up may be required to realize possible mortality benefit in our study.

The failure rate of DS in patients with $\geq 1$ TIMI grade 1 flow was $5.6 \%$. Despite being an unselected population, failure rate in our study is significantly lower than previously reported (about 17-18\%) [5, 39]. This may be due to a lower doorto-balloon time, uniform use of the second generation DES, greater use of ticagrelor, high operator expertise being a high volume center for STEMI and younger population with less calcified lesions. IVUS guidance may be used to further decrease the likelihood of unsuccessful DS attempts by accurate determination of plaque and calcium distribution and suggesting the presence of undilatable lesions [39].

\section{Study limitations}

The strengths of this study were a large sample size and prospective design. However, there were significant limitations also to the present study. First, this was a single centre pilot study and the results can only be hypothesis generating. Second, the poor outcomes in the PD group may be due to higher number of smokers and lower LVEF at presentation. Moreover, studies included in the meta-analyses showing benefit of DS mostly utilised 1st generation DES and poorly reflect current clinical practice $[8,17,40]$. However, we exclusively used 2nd generation DES and managed patients according to current standard of care in a real-world setting. Third, balloon progression through an occlusive thrombus could be associated with distal embolization. However, the deflated semicompliant balloon has a much smaller diameter and a better crossing profile than the aspiration thrombectomy catheter. An indirect proof of safety of this technique lies in very rare incidence of complications $(0.3 \%)$. Finally, the findings of this study are subject to confounding and bias that are inherent to the observational studies. However, a randomised study can't be done as the motive of the technique is maximisation of direct stenting.

\section{Conclusions}

The DBDS technique to facilitate DS appears to be simple, feasible and safe. It significantly increases DS and could offer an alternative to PD and thrombectomy. In real-world clinical practice, DS in STEMI was associated with better clinical and procedural outcomes in comparison with balloon PD and/ or thrombectomy. However, larger studies with longer follow up are mandatory before a routine clinical use can be recommended.

\section{Financial Support}

None.

\section{Conflict of Interest}

None.

\section{References}

1. Menees DS, Peterson ED, Wang Y, Curtis JP, Messenger JC, Rumsfeld JS, Gurm HS. Door-to-balloon time and mortality among patients undergoing primary PCI. N Engl J Med. 2013;369(10):901-909.

2. Keeley EC, Boura JA, Grines CL. Primary angioplasty versus intravenous thrombolytic therapy for acute myocardial infarction: a quantitative review of 23 randomised trials. Lancet. 2003;361(9351):13-20.

3. Seto A, Kern M. Direct stenting for STEMI: does it really make a difference? Catheter Cardiovasc Interv. 2014;84(6):932-933.

4. Ellis SG, Tendera M, de Belder MA, van Boven AJ, Widimsky P, Janssens L, Andersen HR, et al. Facilitated PCI in patients with ST-elevation myocardial infarction. N Engl J Med. 2008;358(21):2205-2217.

5. Barbato E, Marco J, Wijns W. Direct stenting. Eur Heart J. 2003;24(5):394-403.

6. Elgendy AY, Elgendy IY, Mahmoud AN, Bavry AA. Long-term outcomes with aspiration thrombectomy for patients undergoing primary percutaneous coronary intervention: A meta-analysis of randomized trials. Clin Cardiol. 2017;40(8):534-541.

7. Levine GN, Bates ER, Blankenship JC, Bailey SR, Bittl JA, Cercek B, Chambers CE, et al. 2015 ACC/AHA/ SCAI Focused update on primary percutaneous coro- 
nary intervention for patients with ST-elevation myocardial infarction: an update of the 2011 ACCF/AHA/SCAI guideline for percutaneous coronary intervention and the $2013 \mathrm{ACCF} / \mathrm{AHA}$ guideline for the management of STelevation myocardial infarction: a report of the American College of Cardiology/American Heart Association Task Force on Clinical Practice Guidelines and the Society for Cardiovascular Angiography and Interventions. Circulation. 2016;133(11):1135-1147.

8. Magalhaes MA, Minha S, Lhermusier T, Pendyala L, Escarcega RO, Baker NC, Torguson $\mathrm{R}$, et al. Does direct stenting with drug-eluting stents improve outcome? A meta-analysis of 10,900 patients. Catheter Cardiovasc Interv. 2017;90(2):213-222.

9. O'Gara PT, Kushner FG, Ascheim DD, Casey DE, Jr., Chung MK, de Lemos JA, Ettinger SM, et al. 2013 ACCF/ AHA guideline for the management of ST-elevation myocardial infarction: executive summary: a report of the American College of Cardiology Foundation/American Heart Association Task Force on Practice Guidelines. Circulation. 2013;127(4):529-555.

10. Cutlip DE, Windecker S, Mehran R, Boam A, Cohen DJ, van Es GA, Steg PG, et al. Clinical end points in coronary stent trials: a case for standardized definitions. Circulation. 2007;115(17):2344-2351.

11. Niccoli G, Burzotta F, Galiuto L, Crea F. Myocardial noreflow in humans. J Am Coll Cardiol. 2009;54(4):281292.

12. De Luca G, Suryapranata H, Stone GW, Antoniucci D, Biondi-Zoccai G, Kastrati A, Chiariello M, et al. Coronary stenting versus balloon angioplasty for acute myocardial infarction: a meta-regression analysis of randomized trials. Int J Cardiol. 2008;126(1):37-44.

13. Mehta RH, Harjai KJ, Cox DA, Stone GW, Brodie BR, Boura J, Grines L, et al. Comparison of coronary stenting versus conventional balloon angioplasty on five-year mortality in patients with acute myocardial infarction undergoing primary percutaneous coronary intervention. Am J Cardiol. 2005;96(7):901-906.

14. De Luca G, Dirksen MT, Spaulding C, Kelbaek H, Schalij M, Thuesen L, van der Hoeven B, et al. Drug-eluting vs bare-metal stents in primary angioplasty: a pooled patient-level meta-analysis of randomized trials. Arch Intern Med. 2012;172(8):611-621; discussion 621-612.

15. Bangalore S, Amoroso N, Fusaro M, Kumar S, Feit F. Outcomes with various drug-eluting or bare metal stents in patients with ST-segment-elevation myocardial infarction: a mixed treatment comparison analysis of trial level data from 34068 patient-years of follow-up from randomized trials. Circ Cardiovasc Interv. 2013;6(4):378-390.

16. Bailleul C, Puymirat E, Aissaoui N, Schiele F, Ducrocq G, Coste P, Blanchard D, et al. Factors associated with infarct-related artery patency before primary percutaneous coronary intervention for ST-Elevation myocardial infarction (from the FAST-MI 2010 Registry). Am J Cardiol. 2016;117(1):17-21.

17. Azzalini L, Millan X, Ly HQ, L'Allier PL, Jolicoeur EM. Direct stenting versus pre-dilation in ST-elevation myocardial infarction: a systematic review and meta-analysis.
J Interv Cardiol. 2015;28(2):119-131.

18. Capodanno D, Dangas G. Facilitated/pharmaco-invasive approaches in STEMI. Curr Cardiol Rev. 2012;8(3):177180.

19. UpToDate [Internet]. Uptodate.com. 2018 [cited 16 July 2018]. Available from: https://www.uptodate.com/contents/primary-percutaneous-coronary-intervention-inacute-st-elevation-myocardial-infarction-periproceduralmanagement.

20. Ormiston JA, Mahmud E, Turco MA, Popma JJ, Weissman N, Cannon LA, Mann T, et al. Direct stenting with the TAXUS Liberte drug-eluting stent: results from the Taxus Atlas Direct Stent Study. JACC Cardiovasc Interv. 2008;1(2):150-160.

21. Rogers C, Parikh S, Seifert P, Edelman ER. Endogenous cell seeding. Remnant endothelium after stenting enhances vascular repair. Circulation. 1996;94(11):2909-2914.

22. Brueck M, Scheinert D, Wortmann A, Bremer J, von Korn H, Klinghammer L, Kramer W, et al. Direct coronary stenting versus predilatation followed by stent placement. Am J Cardiol. 2002;90(11):1187-1192.

23. Cuisset T, Hamilos M, Melikian N, Wyffels E, Sarma J, Sarno G, Barbato E, et al. Direct stenting for stable angina pectoris is associated with reduced periprocedural microcirculatory injury compared with stenting after predilation. J Am Coll Cardiol. 2008;51(11):1060-1065.

24. Loubeyre C, Morice MC, Lefevre T, Piechaud JF, Louvard Y, Dumas P. A randomized comparison of direct stenting with conventional stent implantation in selected patients with acute myocardial infarction. J Am Coll Cardiol. 2002;39(1):15-21.

25. Capozzolo C, Piscione F, De Luca G, Cioppa A, Mazzarotto P, Leosco D, Golino P, et al. Direct coronary stenting: effect on coronary blood flow, immediate and late clinical results. Catheter Cardiovasc Interv. 2001;53(4):464-473.

26. Wilson SH, Berger PB, Mathew V, Bell MR, Garratt KN, Rihal CS, Bresnahan JF, et al. Immediate and late outcomes after direct stent implantation without balloon predilation. J Am Coll Cardiol. 2000;35(4):937-943.

27. Foley DP, Pieper M, Wijns W, Suryapranata H, Grollier G, Legrand V, de Scheerder I, et al. The influence of stent length on clinical and angiographic outcome in patients undergoing elective stenting for native coronary artery lesions; final results of the Magic 5L Study. Eur Heart J. 2001;22(17):1585-1593.

28. Achkouty G, Dillinger JG, Sideris G, Manzo-Silberman S, Voicu S, Merat B, Logeart D, et al. Microcatheterfacilitated primary angioplasty in ST-segment elevation myocardial infarction. Can J Cardiol. 2018;34(1):23-30.

29. De Maria GL, Alkhalil M, Oikonomou EK, Wolfrum M, Choudhury RP, Banning AP. Role of deferred stenting in patients with ST elevation myocardial infarction treated with primary percutaneous coronary intervention: A systematic review and meta-analysis. J Interv Cardiol. 2017;30(3):264-273.

30. Lee JM, Rhee TM, Chang H, Ahn C, Park TK, Yang JH, Song YB, et al. Deferred versus conventional stent implantation in patients with acute ST-segment elevation myocardial infarction: An updated meta-analysis of 10 
studies. Int J Cardiol. 2017;230:509-517.

31. Qiao J, Pan L, Zhang B, Wang J, Zhao Y, Yang R, Du $\mathrm{H}$, et al. Deferred versus immediate stenting in patients with ST-segment elevation myocardial infarction: a systematic review and meta-analysis. J Am Heart Assoc. 2017;6(3): 004838.

32. Belle L, Motreff P, Mangin L, Range G, Marcaggi X, Marie A, Ferrier N, et al. Comparison of immediate with delayed stenting using the minimalist immediate mechanical intervention approach in acute ST-segment-elevation myocardial infarction: the MIMI study. Circ Cardiovase Interv. 2016;9(3): 0003388.

33. Carrick D, Oldroyd KG, McEntegart M, Haig C, Petrie MC, Eteiba H, Hood S, et al. A randomized trial of deferred stenting versus immediate stenting to prevent no- or slow-reflow in acute ST-segment elevation myocardial infarction (DEFER-STEMI). J Am Coll Cardiol. 2014;63(20):2088-2098.

34. Dziewierz A, Siudak Z, Rakowski T, Kleczynski P, Zasada W, Dubiel JS, Dudek D. Impact of direct stenting on outcome of patients with ST-elevation myocardial infarction transferred for primary percutaneous coronary intervention (from the EUROTRANSFER registry). Catheter Cardiovasc Interv. 2014;84(6):925-931.

35. Piscione F, Piccolo R, Cassese S, Galasso G, D'Andrea
C, De Rosa R, Chiariello M. Is direct stenting superior to stenting with predilation in patients treated with percutaneous coronary intervention? Results from a meta-analysis of 24 randomised controlled trials. Heart. 2010;96(8):588-594.

36. Li C, Zhang B, Li M, Liu J, Wang L, Liu Y, Wang Z, et al. Comparing direct stenting with conventional stenting in patients with acute coronary syndromes: a meta-analysis of 12 clinical trials. Angiology. 2016;67(4):317-325.

37. Ijsselmuiden AJ, Tangelder GJ, Cotton JM, Vaijifdar B, Kiemeneij F, Slagboom T, v d Wieken R, et al. Direct coronary stenting compared with stenting after predilatation is feasible, safe, and more cost-effective in selected patients: evidence to date indicating similar late outcomes. Int J Cardiovase Intervent. 2003;5(3):143-150.

38. Caluk J, Osmanovic E, Barakovic F, Kusljugic Z, Terzic I, Caluk S, Sofic A. Direct coronary stenting in reducing radiation and radiocontrast consumption. Radiol Oncol. 2010;44(3):153-157.

39. Magalhaes MA, Minha S, Pichard AD. Should every drug-eluting stent be deployed directly? JACC Cardiovasc Interv. 2014;7(7):759-760.

40. Belardi JA, Albertal M. Direct stenting versus balloon predilation: Jury is still out. Catheter Cardiovasc Interv. 2017;90(2):223-224. 